\section{Experimental study on efficacy of compression systems with a high static stiffness index for treatment of venous ulcer patients}

\author{
Anneke Andriessen, ${ }^{1}$ Martin Abel $^{2}$ \\ 1 Andriessen Consultants, Malden \& UMC \\ St. Radboud, Nijmegen, The Netherlands; \\ ${ }^{2}$ Medical \& Regulatory Affairs, Lohmann \\ \& Rauscher, Rengsdorf, Germany
}

\section{Abstract}

The experimental study measured interface pressure and static stiffness index of four different compression systems in fifty-two healthy volunteers. For the study interface pressure $(3 \mathrm{~cm} \emptyset$ probe was placed at the anatomical B1 point) was recorded on application of the compression systems every 15 min for $4 \mathrm{~h}$, in supine, standing, while sitting and during walking. For this purpose a portable Kikuhime (Harada Corp., Osaka, Japan) device was used. Further static stiffness index (SSI) was calculated. The evaluated systems were: short stretch bandage system (SSB) Rosidal sys (Lohmann \& Rauscher, Rengsdorf, Germany), multi-layer bandaging (LSB) Profore (Smith \& Nephew, Hull, UK), varistretch bandage (VSB) Proguide (Smith \& Nephew) and tubular compression (CS) Rosidal mobil (Lohmann \& Rauscher). The mean interface pressure of SSB, LSB and VSB was significantly higher $(\mathrm{P}<0.05)$ in each position measured over $4 \mathrm{~h}$, compared to $\mathrm{CS}$. In supine VSB showed high-pressure levels, up to $60 \mathrm{mmHg}$, which remained high. The other systems had more tolerable levels of about 30 $\mathrm{mmHg}$. Interface pressure exerted on limbs is an indicator of their clinical effect. The experimental study results showed different patterns of interface pressure and SSI, which may enable clinicians to predict the frequency of bandage application, supporting an adequate and safe choice of bandage system.

\section{Introduction}

The paper was presented at the International Compression Club Meeting in Vienna 2012 and discussed an experimental study that was previously published. ${ }^{1}$ The study aimed to compare interface pressure and static stiffness index (SSI) of four different compression systems that are currently in use for venous leg ulcer and lymphedema treatment of the lower limbs.

\section{Materials and Methods}

For the experimental study fifty-two ambulatory adults with healthy legs, were recruited at random in the study center, after they had given informed consent. ${ }^{1}$ Excluded were those with an allergy against one of the used materials; arterial occlusive disease (ABPI less than 0.8 ); ulcers on the lower limb; lower limb edema; known history of dermatological problems such as eczema or cellulites. The evaluated systems were: short stretch bandage system (SSB) Rosidal sys (Lohmann \& Rauscher, Rengsdorf, Germany), multi-layer bandaging (LSB) Profore (Smith \& Nephew, Hull, UK), vari-stretch bandage (VSB) Proguide (Smith \& Nephew) and tubular compression (CS) Rosidal mobil (Lohmann \& Rauscher).
Correspondence: Anneke Andriessen, Zwenkgras 25, 6581 RK Malden, The Netherlands. Tel. 3124 3587086 .

E-mail: anneke.a@tiscali.nl

Key words: interface pressure, static stiffness index, compression for venous leg ulcers.

Conference presentation: part of this paper was presented at the International Compression Club (ICC) Meeting on Stiffness of Compression Devices, 2012 May 25, Vienna, Austria (http://www.icc-compressionclub.com/).

Contributions: the authors contributed equally.

Conflict of interests: MA is an employee of Lohmann \& Rauscher (Rengsdorf, Germany), the company that provided the study products. A limited educational grant was received from Lohmann \& Rauscher for conducting the study.

Received for publication: 4 October 2012. Revision received: 1 November 2012.

Accepted for publication: 15 November 2012.

This work is licensed under a Creative Commons Attribution 3.0 License (by-nc 3.0).

(C) Copyright A. Andriessen and M. Abel, 2013

Licensee PAGEPress, Italy

Veins and Lymphatics 2013; 2:e8

doi:10.4081/vl.2013.e8

Interface pressure (IP) (3 $\mathrm{cm} \emptyset$ probe was placed at the anatomical B1 point) was recorded on application of the compression systems and every $15 \mathrm{~min}$ for $4 \mathrm{~h}$, in supine, standing, while sitting and during walking. For this purpose a portable Kikuhime (Harada Corp., Osaka, Japan) device was used. Measurements during walking were recorded while subjects walked on a treadmill for at least 5 min at normal pace.

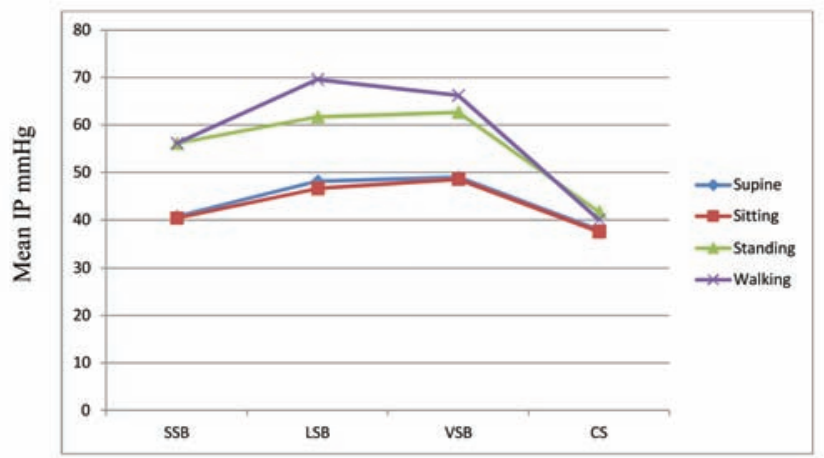

Figure 1. Mean interface pressure in supine, sitting, standing and walking $(\mathrm{N}=52)$. IP, interface pressure; $\mathrm{SSB}$, short stretch bandage system; LSB, multi-layer bandaging; VSB, vari-stretch bandage; CS, tubular compression.

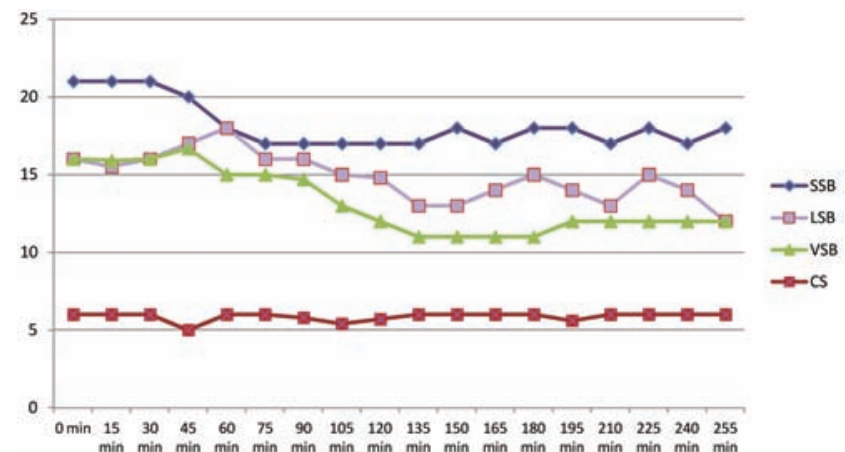

Figure 2. Static stiffness index $(\mathrm{N}=52)$. SSB, short stretch bandage system; LSB, multi-layer bandaging; VSB, vari-stretch bandage; CS, tubular compression. 


\section{Primary outcome measure}

Interface pressure measured in supine, sitting, standing and walking and SSI. Parametric or non-parametric tests (SPSS: IBM Corp., Armonk, NY, USA) were used where appropriate. Mann-Whitney U or paired T-test were used for intragroup and per group comparisons of the IP measured in the different positions and over time.

\section{Results}

The mean interface pressure of SSB, LSB and VSB was significantly higher $(\mathrm{P}<0.05)$ in each position measured over $4 \mathrm{~h}$, compared to CS (Figure 1). In supine VSB showed highpressure levels, up to $60 \mathrm{mmHg}$, which remained high. The other systems had more tolerable levels of $30 \mathrm{mmHg}$. Measurements in sitting showed similar trends. All compression systems maintained pressure levels in walking of at least $40 \mathrm{mmHg}$ (Table 1). The SSI was the highest for SSB with 20 and remained 19 throughout the study period. LSB followed with an SSI of 18, reduced to 15 , where the SSI for VSB went from 17 to 12 and CS with an SSI of 6 lagged behind (Figure 2).

\section{Discussion}

The IP for LSB and VSB in supine of \pm 60 $\mathrm{mmHg}$ were higher than usually reported. LSB and VSB are defined systems, SSB is a variety of compression systems. LSB has an elastic layer (extensibility $>100 \%$ ), SSB consists of short-stretch materials (extensibility $\pm 70 \%$ ). By applying LSBs' elastic layers over each other, with a cohesive bandage as the outer layer, the final system is stiffer. ${ }^{2}$ This was also shown in our study ${ }^{1}$ and is in line with what was demonstrated by Mosti and Partsch. ${ }^{2-5}$
In a clinical study ${ }^{6-8}$ two groups were treated with compression and one group received no compression. In selected patients IP and SSI was measured for the two compression systems LSB and SSB. The static stiffness index remained higher than 10 in both compression groups for one week, the duration of bandage application, despite of bandage pressure loss (Figure 3). The reduction in ulcer area from weeks 12 to 24 in the LSB group and usual care group (moist wound healing dressings, no compression) was not significant $(\mathrm{P}=0.67$ and $\mathrm{P}=0.16$ ), where a statistically significant reduction in ulcer area was observed in the $\mathrm{SSB}$ group ( $\mathrm{P}=0.047$ ) (Figure 4$)$. Both compression systems treated groups showed effective ulcer healing with faster and better ulcer area and pain reduction for SSB, which may be explained by the higher SSI of the system.

\section{Limitations}

This was an experimental study on healthy

Table 1. Experimental study $(\mathrm{N}=52)$ : interface pressure measured in supine and walking.

\begin{tabular}{|c|c|c|c|c|c|c|c|c|c|}
\hline \multirow[t]{2}{*}{$\mathrm{mmHg}$} & \multicolumn{2}{|c|}{ SSB } & \multicolumn{2}{|c|}{ LSB } & \multicolumn{2}{|c|}{ VSB } & \multicolumn{2}{|c|}{ CS } & \multirow[t]{2}{*}{ Paired T-test } \\
\hline & Supine & Walking & Supine & Walking & Supine & Walking & Supine & Walking & \\
\hline $\begin{array}{l}\text { Mean } \\
( \pm \text { SD })\end{array}$ & $40.68( \pm 5.01)$ & $56.11( \pm 5.01)$ & $48.12( \pm 4.57)$ & $69.59( \pm 6.24)$ & $48.96( \pm 3.99)$ & $66.21( \pm 4.02)$ & $37.82( \pm 0.58)$ & $40.04( \pm 1.77)$ & $\begin{array}{l}\text { Supine: SSB, LSB, } \\
\text { VSB us CS: } P=0.05\end{array}$ \\
\hline $\begin{array}{l}\text { Median } \\
\text { (range) }\end{array}$ & $41(39-60)$ & $57(52-80)$ & $50(44-59)$ & $73(64-90)$ & $51(46-60)$ & $69(64-80)$ & $40(39-41) 42$ & $(40-45)$ & $\begin{array}{l}\text { Walking: SSB, LSB, } \\
\text { VSB us CS: } \mathrm{P}=0.05\end{array}$ \\
\hline
\end{tabular}

SSB, short stretch bandage system; LSB, multi-layer bandaging; VSB, vari-stretch bandage; CS, tubular compression; SD, standard deviation.

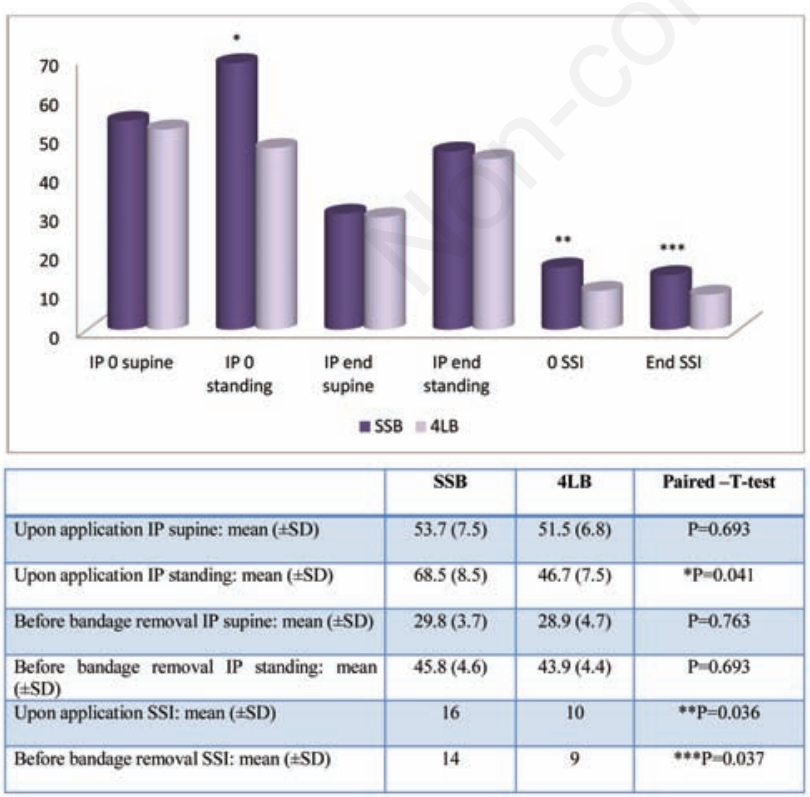

Figure 3. Clinical study $(\mathrm{N}=321)$ : interface pressure and static stiffness index. IP, interface pressure; SSI, static stiffness index; SSB, short stretch bandage system; 4LB, four-layer bandage system; SD, standard deviation.

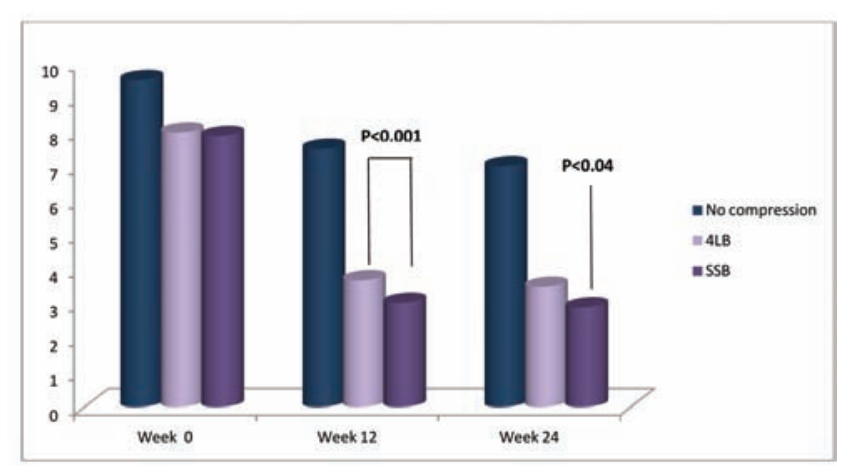

\begin{tabular}{|lc|c|c|c|c|}
\hline \multicolumn{2}{|c|}{ Uleer area $\mathrm{cm}^{2}$} & SSB & 4LB & UC & ANOVA \\
\hline $\begin{array}{l}\text { Week } \\
( \pm \text { SD })\end{array}$ & $0: \quad$ mean & $7.56(10.43)$ & $7.54(9.95)$ & $9.23(12.50)$ & $\mathrm{P}=0.493$ \\
\hline $\begin{array}{l}\text { Week } \\
( \pm \mathrm{SD})\end{array}$ & $12: \quad$ mean & $3.00(8.40)$ & $3.48(8.54)$ & $7.54(12.45)$ & $\mathrm{P}<0.001$ \\
\hline $\begin{array}{l}\text { Week } \\
( \pm \mathrm{SD})\end{array}$ & $12: \quad$ mean & $* 2.85(8.18)$ & $3.39(8.64)$ & $6.90(10.62)$ & $* \mathrm{P}=0.047$ \\
\hline
\end{tabular}

Figure 4. Clinical study $(\mathrm{N}=321)$ : ulcer area reduction at 12 and at 24 weeks. SSB, short stretch bandage system; 4LB, four-layer bandage system; UC, usual care (a moist wound healing dressing and no compression); ANOVA, analysis of variance; $\mathrm{SD}$, standard deviation. 
legs over a 4-h period where typically the systems are left in place for 3-4 days up to 1 week. Moreover the device that was used to measure IP is not suitable to leave in place for over $4 \mathrm{~h}$. Based on our results it is not possible to predict what the pressure levels would be over this period on for instance venous leg ulcer patients with edema.

However the reported results from a clinical study, ${ }^{6,7}$ suggest that when using the SSB and LSB compression systems in venous leg ulcer patients with edema, the IP levels are maintained at a therapeutic level over a week. For this study another, more suitable measurement device [Picopress®, Microlab Elettronica Sas, Roncaglia di Ponte San Nicolò (PD), Italy $]^{3}$ was used to measure IP levels. This device can be left in place for several days up to a week, providing clinically relevant information. ${ }^{3}$

\section{Conclusions}

Interface pressure exerted on limbs is an indicator of their clinical effect. The study results showed different patterns of interface pressure and SSI, which may enable clinicians to predict the frequency of bandage application, supporting an adequate and safe choice of bandage system. This approach may increase the patients' participation in, and compliance with, compression therapy, thereby saving on costs and nursing time.

\section{References}

1. Wong IKY, Man MBL, Chan OSH, et al. Interface pressure and static stiffness index of four compression systems. J Wound Care 2012;21:161, 164, 166-7.

2. Mosti G, Mattaliano V, Partsch H. Inelastic compression increases venous ejection fraction more than elastic bandages in patients with superficial venous reflux. Phlebology 2008;23:287-94.

3. Mosti G, Partsch H. Inelastic bandages maintain their hemodynamic effectiveness over time despite significant pressure loss. J Vasc Surg 2010;52:925-31.

4. Mosti G, Mattaliano V, Partsch H. Influence of different materials in multicomponent bandages on pressure and stiffness of the final bandage. Dermatol Surg 2008;34:6319.

5. Partsch $\mathrm{H}$. The use of pressure change on standing as a surrogate measure of the stiffness of a compression bandage. Eur $\mathrm{J}$ Vasc Endovasc Surg 2005;30:415-21.

6. Wong IKY, Andriessen A, Charles HE, et al. Randomized controlled trial comparing treatment outcome on quality of life of two compression bandaging systems and standard care without compression in patients with venous leg ulcers. JEADV 2012;26: 102-10.

7. Wong IYK, Andriessen A, Lee DTF, et al. Randomized controlled trial comparing treatment outcome of two compression bandaging systems and standard care without compression in patients with venous leg ulcers. J Vasc Surg 2012;55: 1376-85.

8. Partsch H. The static stiffness index (SSI): a simple method to assess the elastic property of compression material in vivo. Dermatol Surg 2005;31:625-30. 